Int. J. Electrochem. Sci., 11 (2016) $9881-9890$

\title{
Synthesis of N-doped carbon by microwave-assisited pyrolysis ionic liquid for lithium-ion batteries
}

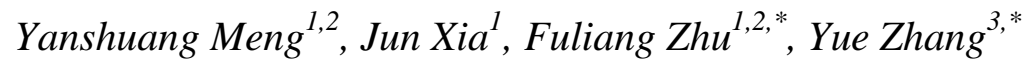 \\ ${ }^{1}$ School of Materials Science and Engineering, Lanzhou University of Technology, Lanzhou \\ 730050, China \\ ${ }^{2}$ State Key Laboratory of Advanced Processing and Recycling of Non-ferrous Metals, Lanzhou \\ 730050,China \\ ${ }^{3}$ Department of Industrial Engineering, Texas Tech University, Lubbock, Texas, 79409, USA) \\ *E-mail: chzfl@126.com, yue.zhang@ttu.edu
}

doi: $10.20964 / 2016.12 .08$

Received: 26 August 2016 / Accepted: 17 October 2016 / Published: 10 November 2016

\begin{abstract}
Nitrogen-doped carbon (NDC) was prepared by a novel microwave-assisted pyrolysis of ionic liquid method. The carbonation temperature and time of the ionic liquid were obviously dropped down by microwave-assisted pyrolysis. The results of XRD, Raman spectra and FT-IR spectra indicated that the pyrolysis product was graphitic nitrogen-doped carbon. The nitrogen dopant in NDC created a porous structure and a large number of defects, which introduced many active sites for the $\mathrm{Li}^{+}$ion adsorption. Consequently, the NDC delivered high electrochemical performances when used as anode for lithium ion batteries. The NDC electrode exhibited a specific capacity of $243.6 \mathrm{mAh} . \mathrm{g}^{-1}$ after 50 cycles at $0.2 \mathrm{C}$ and $196 \mathrm{mAh} . \mathrm{g}^{-1}$ after 50 cycles at $1.0 \mathrm{C}$.
\end{abstract}

Keywords: Nitrogen-doped carbon, Microwave-assisted pyrolysis, Ionic liquid

\section{FULL TEXT}

(C) 2016 The Authors. Published by ESG (www.electrochemsci.org). This article is an open access article distributed under the terms and conditions of the Creative Commons Attribution license (http://creativecommons.org/licenses/by/4.0/). 